\title{
HDAC inhibitors downregulate MRP2 expression in multidrug resistant cancer cells: Implication for chemosensitization
}

\author{
HANNA KIM ${ }^{1}$, SU-NAM KIM ${ }^{2}$, YEON-SUK PARK ${ }^{1}$, NAM HYUN KIM ${ }^{1}$, \\ JEUNG WHAN HAN ${ }^{3}$, HOI YOUNG LEE ${ }^{4}$ and YONG KEE KIM ${ }^{1}$ \\ ${ }^{1}$ Department of Pharmacology, Kwandong University College of Medicine, Gangneung 210-701; \\ ${ }^{2}$ KIST Gangneung Institute, Gangneung 210-340; ${ }^{3}$ College of Pharmacy, Sungkyunkwan University, Suwon 440-746; \\ ${ }^{4}$ Department of Pharmacology, College of Medicine, Konyang University, Daejeon 302-718, Republic of Korea
}

Received July 8, 2010; Accepted September 6, 2010

DOI: $10.3892 /$ ijo.2010.879

\begin{abstract}
Although histone deacetylase (HDAC) inhibitors are emerging as a promising class of cancer chemotherapeutic agents, their effects on multidrug resistance (MDR) are poorly understood. In this study, we investigated whether HDAC inhibitors overcome MDR phenotype. HDAC inhibitors suppress the growth of both MDR positive cancer cells KBV20C and its parental cells KB with similar potencies. In parallel, histone acetylation and $\mathrm{p} 21^{\mathrm{WAF} 1}$ expression by the HDAC inhibitors were similarly increased in both cell types, indicating that these HDAC inhibitors are poor substrates of $\mathrm{ABC}$ drug transporters and effective in MDR cancer cells. In addition, multidrug resistance protein 2 (MRP2) expression is selectively attenuated by HDAC inhibitors, especially SAHA and TSA, in KBV20C cells, whereas MDR1 and BCRP expressions are not affected. This downregulation of MRP2 contributes to increase in paclitaxel-induced $\mathrm{G}_{2} / \mathrm{M}$ arrest and apoptosis, which might be due to intracellular accumulation of paclitaxel. Collectively, our data provide a molecular rationale for the application of HDAC inhibitors to overcome MDR in cancer cells.
\end{abstract}

\section{Introduction}

Multidrug resistance (MDR), by which cancer cells are resistant to many structurally and functionally unrelated anticancer drugs, is a significant impediment in cancer chemotherapy $(1,2)$. The MDR phenotype is often due to

Correspondence to: Dr Su-Nam Kim, KIST Gangneung Institute, Ga-17 Block, Gangneung Techno Valley, Daejeon-dong, Gangneung, Gangwon-do 210-340, Republic of Korea

E-mail: snkim@kist.re.kr

Dr Yong Kee Kim, Department of Pharmacology, Kwandong University College of Medicine, 522 Naegok-dong, Gangneung-si, Gangwon-do 210-701, Republic of Korea

E-mail: yksnbk@kwandong.ac.kr

Key words: HDAC inhibitor, multidrug resistance, MRP2 over-expression of ATP binding cassette $(\mathrm{ABC})$ multidrug transporters, such as P-glycoprotein (P-gp; ABCB1), BCRP (ABCG2), and multidrug resistance proteins (MRPs). P-gp, a $170-\mathrm{kDa}$ transmembrane glycoprotein, is the first human $\mathrm{ABC}$ transporter whose cDNA was cloned and characterized based on its ability to confer a multidrug-resistance phenotype to cancer cells (3). MRP1 (ABCC1) and MRP2 (ABCC2) are identified as multidrug-resistance genes and associated with transport of glutathione conjugates of many toxic compounds $(4,5)$. Breast cancer resistance protein (BCRP; $A B C G 2)$ is a ubiquitous $\mathrm{ABC}$ transmembrane protein that plays a significant role in absorption, distribution, and elimination of its substrate drugs. It also confers resistance in cancer cells to a variety of cancer chemotherapeutic agents such as mitoxantrone, topotecan, and methotrexate (6). These $\mathrm{ABC}$ transporters are able to reduce the intracellular concentrations of taxanes and vinca alkaloids to a nontoxic level, which confer MDR phenotype to cancer cells. In addition, over-expression of these $\mathrm{ABC}$ transporters has been closely correlated with poor prognosis for various human cancers $(2,7)$.

Recently, histone deacetylase (HDAC) inhibitors are appreciated as one of emerging class of anticancer drugs, because HDAC inhibitors promote accumulation of acetylated histones and subsequent induction of a specific pre-programmed set of genes which are required for growth arrest, differentiation and apoptosis. Several HDAC inhibitors, such as vorinostat (suberolanilide hydroxamic acid, SAHA) $(8,9)$, MS275 (10,11), phenylbutyrate (12) and depsipeptide FK228 $(13,14)$, have shown potent anti-tumor activities and are currently in Phase I or II clinical trials. Among them, vorinostat (Zolinza, Merck \& Co., Inc.) has been approved for the treatment of cutaneous T-cell lymphoma (15).

Recent reports demonstrate that HDAC inhibitor treatment increases the expression of P-gp, and subsequent induction of MDR phenotype, which might limit clinical application of HDAC inhibitors (16-19). However, the effects of HDAC inhibitors on MDR cancer cells are poorly investigated. In this study, we investigate the effects of various HDAC inhibitors on MDR cancer cells. Our data show that HDAC inhibitors suppress cell growth with similar potencies in both MDRpositive and -negative cancer cells, which is accompanied by an increase in $\mathrm{p} 21^{\mathrm{WAF}}$ expression and an accumulation 
of acetylated histone. In addition, treatment with HDAC inhibitors, especially SAHA and TSA, leads to a specific downregulation of MRP2, but not MDR1 and BCRP, which is necessary for sensitization of the cancer cells against paclitaxel.

\section{Materials and methods}

Cell culture and cytotoxicity test. Human nasopharyngeal epidermal carcinoma cell line KB was grown in RPMI-1640 medium (Invitrogen, Carlsbad, CA) with 10\% fetal bovine serum (FBS; HyClone Laboratories, Logan, UT) and 1\% penicillin/streptomycin (Invitrogen). The MDR subclone $\mathrm{KBV} 20 \mathrm{C}$ cells were maintained in the medium containing additional $20 \mathrm{nM}$ vincristine (Sigma Chemical, St. Louis, MO) as described previously (20). Paclitaxel, TSA, valproic acid and sodium butyrate were obtained from Sigma, and apicidin, SAHA and MS275 were form Calbiochem (San Diego, CA). Cytotoxicity was determined by the MTS assay (Promega, Madison, WI) according to the manufacturer's instructions.

Cell cycle analysis. KBV20C cells were treated with indicated concentration of paclitaxel and/or HDAC inhibitors for $24 \mathrm{~h}$. Cells were harvested, washed twice with ice-cold PBS and fixed in $70 \%$ ethanol at $-20^{\circ} \mathrm{C}$. Cells were washed with PBS, incubated with $100 \mu \mathrm{g} / \mathrm{ml}$ RNase A at $37^{\circ} \mathrm{C}$ for $30 \mathrm{~min}$, stained with $25 \mu \mathrm{g} / \mathrm{ml}$ propidium iodide (Sigma) and analyzed with flow cytometry.

Apoptosis assays. After treatment of KBV20C cells with HDAC inhibitors and/or paclitaxel for $24 \mathrm{~h}$, cells were harvested, and the extent of apoptosis was determined by flow cytometric analysis using Annexin V-FITC apoptosis detection kit (BD Biosciences, San Diego, CA), according to the manufacturer's description. And, PARP cleavage was analyzed by immunoblot analysis.

Histone isolation. The cells were harvested with PBS and washed with RSB buffer (10 mM Tris-Cl, $10 \mathrm{mM} \mathrm{NaCl}, 3 \mathrm{mM}$ $\mathrm{MgCl}_{2}$ ). Then the cells were homogenized with RSB buffer containing $0.5 \% \mathrm{NP}-40$ using loose-fitting glass homogenizer (10 strokes). After centrifuging at $1000 \mathrm{x}$ g for $10 \mathrm{~min}$, the pellet was resuspended in $0.8 \mathrm{M} \mathrm{HCl}$ solution containing $5 \mathrm{mM}$ $\mathrm{MgCl}_{2}$, and then incubated for $20 \mathrm{~min}$ on ice. Histone fractions were precipitated by adding $50 \%$ trichloroacetic acid and collected by centrifuging at $12,000 \mathrm{x}$ g for $20 \mathrm{~min}$ at $4^{\circ} \mathrm{C}$. The histone fractions were boiled in Laemmli sample buffer for $3 \mathrm{~min}$, and were resolved by SDS-polyacrylamide gel electrophoresis (PAGE).

Immunoblot analysis. Cells were lysed with $50 \mathrm{mM}$ Tris- $\mathrm{HCl}$ (pH 7.5), $120 \mathrm{mM} \mathrm{NaCl}, 20 \mathrm{mM} \mathrm{NaF}, 1 \mathrm{mM}$ EDTA, $5 \mathrm{mM}$ EGTA, $15 \mathrm{mM}$ sodium pyrophosphate, $30 \mathrm{mM}$ p-nitrophenyl phosphate, $1 \mathrm{mM}$ benzamidine, $0.1 \mathrm{mM}$ phenylmethylsulfonyl fluoride, and $1 \%$ Nonidet P-40 for $20 \mathrm{~min}$ at $4{ }^{\circ} \mathrm{C}$ and centrifuged at $15,000 \mathrm{x} \mathrm{g}$ for $15 \mathrm{~min}$ at $4^{\circ} \mathrm{C}$. Cell lysates were boiled in Laemmli sample buffer for $3 \mathrm{~min}$, and $30 \mu \mathrm{g}$ of protein was subjected to SDS-PAGE. Proteins were then transferred to polyvinylidene difluoride membranes. The membranes were blocked for $30 \mathrm{~min}$ in Tris-buffered saline (TBS) containing $0.1 \%$ Tween-20 and 5\% (w/v) dry skim milk powder and incubated overnight with primary antibodies to p21 ${ }^{\mathrm{WAF}}$, PARP (Santa Cruz Biotechnology, Santa Cruz, CA), Acetyl-histone H3, Histone H3, and $\alpha$-tubulin (Cell Signaling, Beverly, MA). The membranes were then washed with TBS- $0.1 \%$ Tween-20, incubated for $1 \mathrm{~h}$ with a secondary antibody, and visualized with an enhanced chemiluminescence detection kit (Amersham Life Sciences, IL).

$R T-P C R$. Total RNA was extracted using the easy-BLUE ${ }^{\mathrm{TM}}$ total RNA extraction kit (iNtRON Biotechnology, Sungnam, Korea), and the integrity of the RNA was checked by agarose gel electrophoresis and ethidium bromide staining. One microgram of RNA was used as a template for each reverse transcriptase (RT)-mediated PCR (RT-PCR) reaction using the ImProm-II Reverse Transcription System (Promega) and Taq polymerase (Solgent, Daejeon, Korea). The PCR primer sets were 5'-CCCATCATTGCAATAGCAGG-3' and 5'-GTTCAAACTTCTGCTCCTGA-3' for P-gp; 5'-ATGTCA CGTGG AATACCACG-3' and 5'-GAAGACTGAACTCCC TTCCT-3' for MRP1; 5'-ACAGAGGCTG GTGGCAACC-3' and 5'-ACCATTACCTTGTCACTGTCC-3' for MRP2; 5'GAT CACAGT CTTCAAGGAGATC-3' and 5'-CAGTCCC AGTACGACTGTGACA-3' for BCRP; 5'-CTCATGACCAC AGTCCATGCC ATC-3' and 5'-CTGCTTCACCACCTTCT TGATGTC-3' for GAPDH.

\section{Results}

Growth inhibition of MDR-positive cancer cells by HDAC inhibitors. In order to evaluate the therapeutic potential of HDAC inhibitors on MDR cancer cells, we first determined the effects of various HDAC inhibitors on the proliferation of MDR positive cells KBV20C. Since KBV20C cells are more resistant to chemotherapeutic agents through over-expression of $\mathrm{ABC}$ transporter genes, the cells are widely used for studying MDR. As seen in Table I, KBV20C cells are more resistant to paclitaxel and vincristine, compared to parental line KB cells (up to 360- and 715-fold, respectively). Most of HDAC inhibitors (TSA, SAHA, MS275, valproic acid, and sodium butyrate) showed similar cytotoxicities against both $\mathrm{KB}$ and KBV20C cells (Table I), indicating that these HDAC inhibitors might be poor substrates of ABC drug efflux pumps, and be sufficiently accumulated into cancer cells to exert their growth inhibition effects. However, effect of apicidin was distinguished from the other HDAC inhibitor effects. The growth inhibitory effect of apicidin against KBV20C cells was weaker, comparing to $\mathrm{KB}$ cells; the $\mathrm{IC}_{50}$ value was shifted from $0.42 \mu \mathrm{M}$ (in $\mathrm{KB}$ cells) to $5.75 \mu \mathrm{M}$ (in KBV20C cells) (Table I). Taken together, these results suggest that most of HDAC inhibitors except apicidin inhibit the growth of both MDR-positive and -negative cells with similar potencies.

Changes in histone acetylation levels and p21 $1^{\text {WAF1 }}$ expression by HDAC inhibitors in KBV20C cells. It has been well demonstrated that HDAC inhibitors induces $\mathrm{p} 21^{\mathrm{WAF} 1}$ gene expression through histone hyperacetylation of its promoter region, leading to cell cycle arrest (21-23). We next examined whether 
Table I. Growth inhibition by various HDAC inhibitors in $\mathrm{KB}$ and KBV20C cells. ${ }^{\mathrm{a}}$

\begin{tabular}{lccc}
\hline & \multicolumn{3}{c}{$\mathrm{IC}_{50}(\mu \mathrm{M})$} \\
\cline { 2 - 4 } HDAC inhibitors & $\mathrm{KB}$ & $\mathrm{KBV} 20 \mathrm{C}$ & Fold \\
\hline Paclitaxel & 0.004 & 1.44 & 360 \\
Vincristine & 0.008 & 5.72 & 715 \\
Apicidin & 0.42 & 5.75 & 14.7 \\
TSA & 0.13 & 0.10 & 0.78 \\
SAHA & 0.23 & 0.15 & 0.65 \\
MS275 & 0.18 & 0.28 & 1.56 \\
Valproic acid & 18.6 & 36.1 & 1.94 \\
Sod. butyrate & 19.9 & 25.2 & 1.26 \\
\hline
\end{tabular}

${ }^{\mathrm{a}} \mathrm{KB}$ and $\mathrm{KBV} 20 \mathrm{C}$ cells were seeded at a density of $5 \times 10^{3} /$ well in 96-well plates and treated with various concentrations of vincristine, paclitaxel, and HDAC inhibitors (apicidin, MS275, SAHA, TSA, valproic acid, and sodium butyrate) for $48 \mathrm{~h}$. Cell viability was determined using the MTS assay. ${ }^{b} \mathrm{IC}_{50}$ values of these cells are millimolar (mM) concentrations.

HDAC inhibitor could induce p21 $1^{\mathrm{WAF} 1}$ gene expression as well as an accumulation of acetylated histone in MDR cancer cells. Treatment with HDAC inhibitors led to a dose-dependent increase in $\mathrm{p} 21^{\mathrm{WAF} 1}$ expression as well as acetylated histone $\mathrm{H} 3$ in KB cells (Figs. 1 and 2). Similar expression patterns by HDAC inhibitors (SAHA, TSA and MS275) were observed in KBV20C cells. However, the apicidin effect in KBV20C cells was weaker than in KB cells. An accumulation of acetylated histone $\mathrm{H} 3$ in $\mathrm{KB}$ cells appeared at $0.3 \mu \mathrm{M}$ of apicidin and reached maximal accumulation at $1 \mu \mathrm{M}$, while the accumulation in KBV20C cells observed at $1 \mu \mathrm{M}$, and reached maximal accumulation at $10 \mu \mathrm{M}$ (Fig. 1). In addition, apicidin induction of $\mathrm{p} 21^{\mathrm{WAF} 1}$ expression in KBV20C cells required much higher concentration (Fig. 2). These results strongly support the notion that HDAC inhibitors (SAHA, TSA and MS275) are poor substrates of ABC drug efflux pumps.

Specific downregulation of MRP2 by HDAC inhibitors. We next examined the effect of HDAC inhibitors on the expression of $\mathrm{ABC}$ transporter genes. The expression levels of MDR1, MRP1, MRP2 and BCRP were analyzed by RT-PCR. Among them, MDR1, MRP2 and BCRP were highly expressed in KBV20C cells, which might be responsible for MDR phenotype, however, MRP1 was not expressed (Fig. 3). The expression of MDR 1 and BCRP was not affected by HDAC inhibitors (SAHA, TSA, MS275 and apicidin), while MRP2 expression was dose-dependently downregulated by HDAC inhibitors, especially by SAHA and TSA (Fig. 3A). Treatment with $1 \mu \mathrm{M}$ SAHA led to $>50 \%$ decrease in MRP2 expression, and $>90 \%$ decrease was observed at $3 \mu \mathrm{M}$ concentration (Fig. 3A). The effect of TSA was comparable to SAHA's effect. However, MS275 and apicidin slightly decreased the MRP2 expression at $3 \mu \mathrm{M}$ concentration (Fig. 3B).

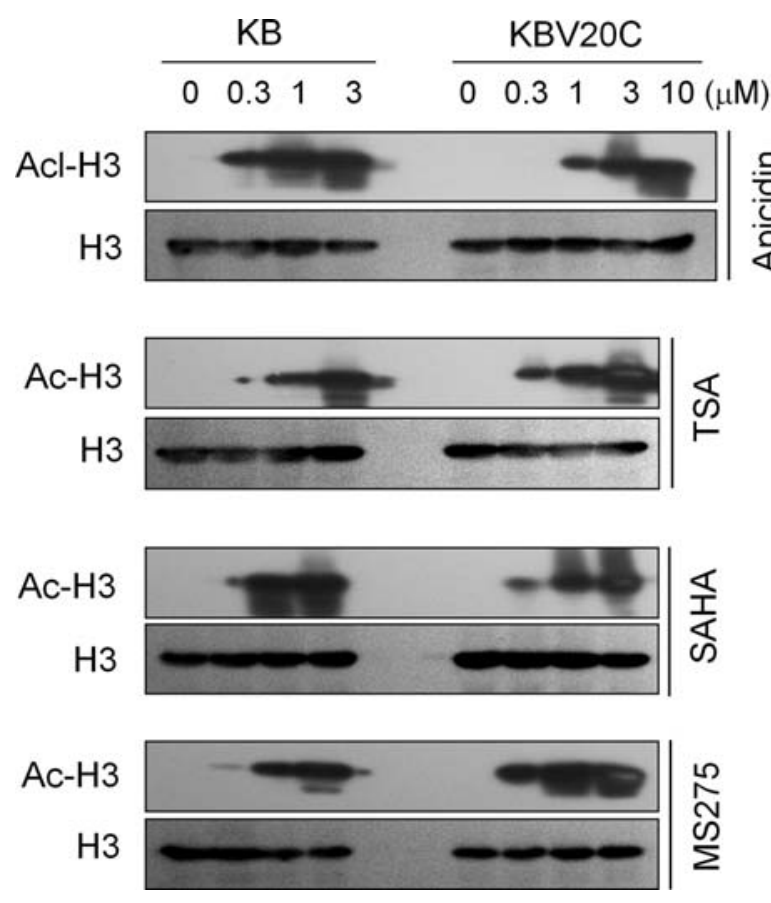

Figure 1. HDAC inhibitors increase the acetylation of histone $\mathrm{H} 3$ in $\mathrm{KB}$ and KBV20C cells. KB and KBV20C cells were exposed to indicated concentration of HDAC inhibitors (apicidin, TSA, SAHA, and MS275) for $24 \mathrm{~h}$. Acetylation levels of histone $\mathrm{H} 3$ were analyzed by immunoblot analysis as described in Materials and methods.

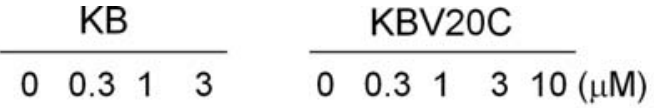
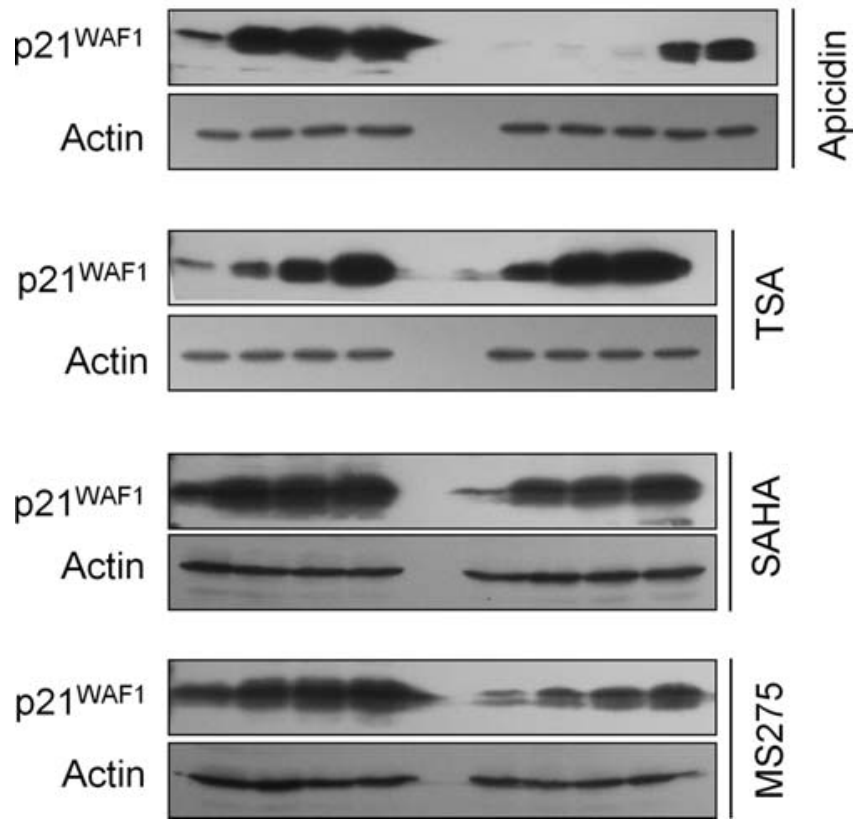

Figure 2. HDAC inhibitors increase $\mathrm{p} 21^{\mathrm{WAF} 1}$ expression in KB and KBV20C cells. $\mathrm{KB}$ and $\mathrm{KBV} 20 \mathrm{C}$ cells were exposed to indicated concentration of HDAC inhibitors (apicidin, TSA, SAHA, and MS275) for 24 h. p2 $1^{\text {WAF1 }}$ expression levels were analyzed by immunoblot analysis as described in Materials and methods.

Concomitantly, MRP2 protein level was decreased by SAHA treatment but not by MS275 (Fig. 3C). These results indicate that MRP2 expression is specifically downregulated by 

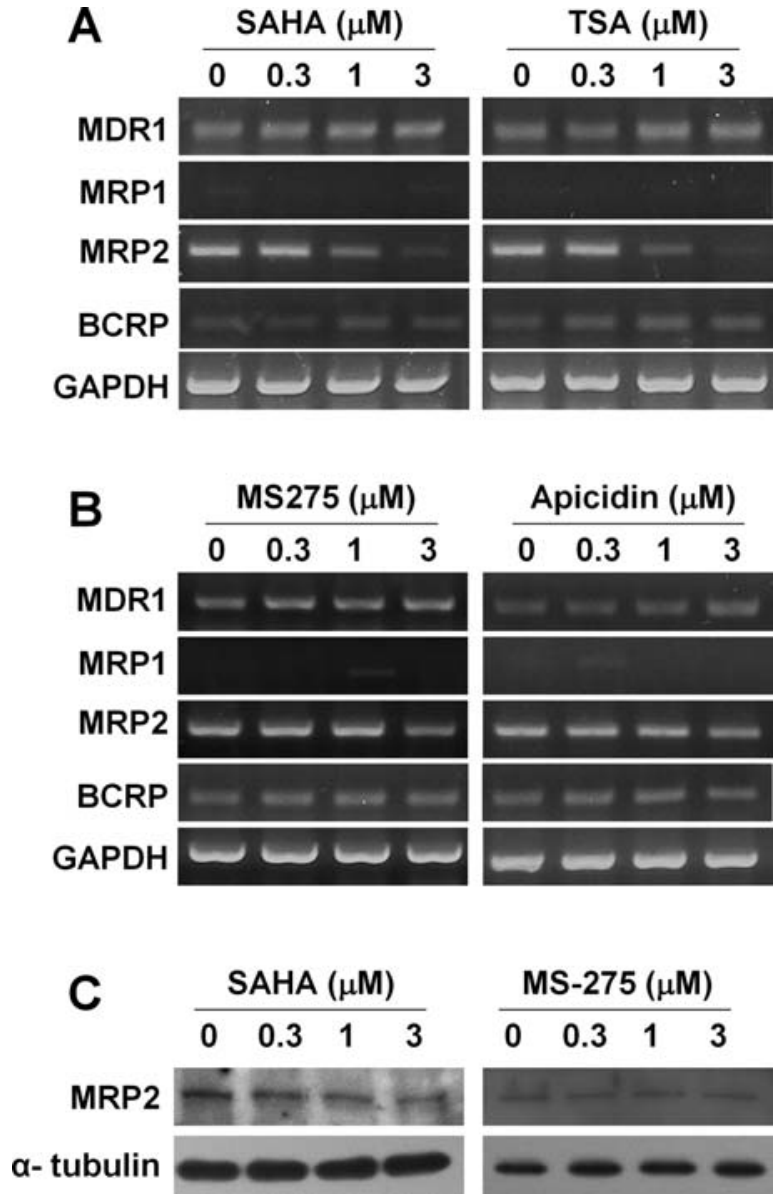

Figure 3. Specific downregulation of MRP2 by HDAC inhibitors in KBV20C cells. (A and B) KBV20C cells were incubated with indicated concentrations of HDAC inhibitors (apicidin, TSA, SAHA, and MS275) for $24 \mathrm{~h}$. The expression levels of ABC transporter genes were assessed by RT-PCR using specific MDR1, MRP1, MRP2, and BCRP primers. (C) After treatment of KBV20C cells with SAHA or MS275, MRP2 expressions were analyzed by immunoblot analysis.

SAHA or TSA and this downregulation may affect MDR phenotype.

Downregulation of MRP2 increases the sensitivity of KBV20C cells to paclitaxel. It is known that paclitaxel induces cell cycle arrest at mitotic stage via disrupting micro-tubule function and has apoptotic potential $(24,25)$. In addition, recent reports show that MRP2 transports taxanes and confers substantial resistance against paclitaxel (26). We thus examined whether downregulation of MRP2 by SAHA could affect the actions of paclitaxel. We first analyzed the cell cycle progression in the presence of SAHA and/or paclitaxel. For this experiment, we chose the minimal concentration of paclitaxel at which the cell cycle of KBV20C cells was not affected (Fig. 4). Single treatment with SAHA or MS275 led to an increase in the cell population at $\mathrm{G}_{0} / \mathrm{G}_{1}$ phase (Fig. 4), which seemed to be mediated by inhibition of CDKs through p $21^{\mathrm{WAF} 1}$ induction. However, paclitaxel in combination with SAHA led to an increase in $\mathrm{G}_{2} / \mathrm{M}$ phase cells, but not with MS275 (Fig. 4), which was well correlated with the previous observations that MRP2 is specifically downregulated by SAHA but not by MS275. These results imply that specific

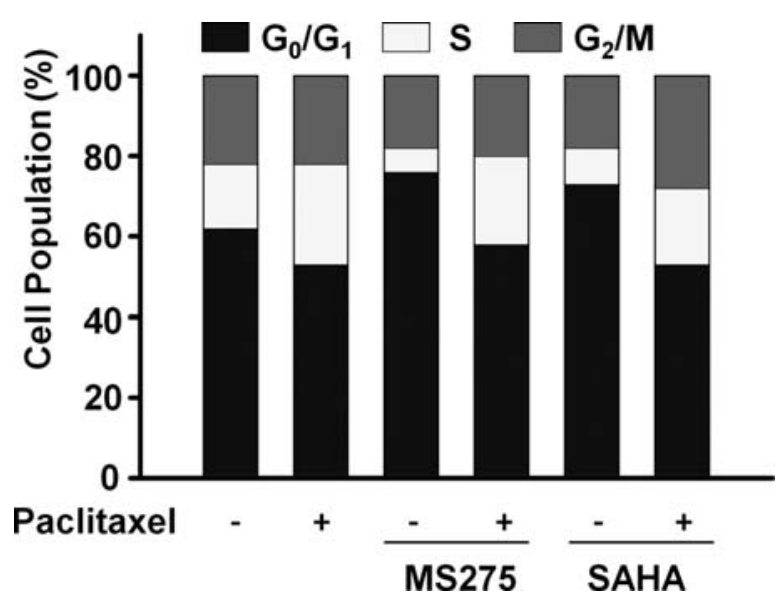

Figure 4. SAHA treatment potentiates paclitaxel-induced $\mathrm{G}_{2} / \mathrm{M}$ arrest in KBV20C cells. KBV20C cells were treated with $2 \mathrm{nM}$ paclitaxel and/or $1 \mu \mathrm{M}$ MS275 or SAHA for $24 \mathrm{~h}$. After staining with propidium iodide, cell cycle was analyzed using flow cytometry.

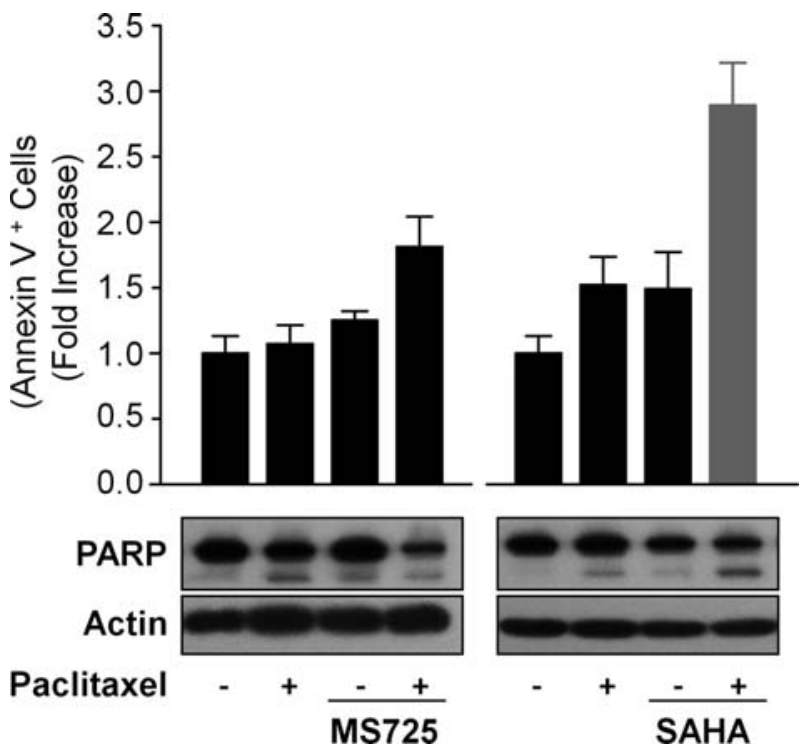

Figure 5. SAHA treatment potentiates paclitaxel induction of apoptosis in KBV20C cells. KBV20C cells were treated with $2 \mathrm{nM}$ paclitaxel and/or $1 \mu \mathrm{M}$ MS275 or SAHA for $24 \mathrm{~h}$. The cells were incubated with fluorescence-labeled Annexin $\mathrm{V}$ and subjected to flow cytometry. Apoptotic cell death was evaluated as the percentage of Annexin V-positive cells. PARP cleavage was examined by immunoblot analysis.

downregulation of MRP2 by SAHA leads to an increase in intracellular accumulation of paclitaxel which is responsible for mitotic arrest. To confirm this notion, we examined the effect of SAHA on the paclitaxel-induced apoptosis. As shown in Fig. 5, treatment with SAHA or MS275 alone did not increase apoptosis, whereas combination treatment with SAHA and paclitaxel synergistically increased apoptosis, as evidenced by the increase in Annexin V-positive cells as well as in PARP cleavage. However, MS275 treatment failed to increase the paclitaxel-induced apoptosis (Fig. 5). These results strongly support the notion that SAHA-mediated 
downregulation of MRP2 contributes to the sensitization of cancer cells to paclitaxel.

\section{Discussion}

Chemotherapy is the most effective treatment for metastatic cancers. The effectiveness of chemotherapy, however, is seriously limited by MDR which is mainly due to the overexpression of $\mathrm{ABC}$ drug transporters $(1,2)$. ABC drug transporters function as drug efflux pumps which actively transport anticancer drugs from the inside to the outside of cancer cells and decrease the intracellular accumulation of anticancer drugs inside cancer cells necessary for cytotoxic activity. Therefore, novel agents which can inhibit the drug transporter function of $\mathrm{ABC}$ drug transporters or its expression have the potential to overcome the MDR phenotype by enhancing intracellular accumulation of anticancer drugs. The present study shows that HDAC inhibitors, especially SAHA and TSA, specifically downregulate the expression of MRP2 in MDR cancer cell lines, but not MDR1 and BCRP expressions (Fig. 3). In addition, this downregulation of MRP2 is closely associated with synergistic increase in paclitaxelinduced $\mathrm{G}_{2} / \mathrm{M}$ arrest and apoptosis (Figs. 4 and 5). These findings imply that HDAC inhibitors, especially SAHA, might be useful for MDR cancer treatment. At present time we cannot explain the exact molecular mechanism for the specific downregulation of MRP2. Recent report shows that DNA methyltransferase 1 is downregulated by treatment with HDAC inhibitor, resulting from the formation of transcriptional repressive complex on the promoter region (27). So, it is possible that similar repressive complexes might be specifically recruited to the MRP2 promoter region by HDAC inhibitors, which is in need of future study. Our observation that apicidin (HDAC 2 and 3 inhibitor) and MS275 (HDAC 1, 2, 3, and 9 inhibitor) do not downregulate MDR2 in contrast to the pan-HDAC inhibitors TSA and SAHA might point to class II HDACs as potential targets in mediating the MRP2 downregulation.

Recent accumulating evidences strongly suggests that HDAC inhibitors are a novel class of anticancer drugs. HDAC inhibitors induce a specific pre-programmed set of genes which are required for growth arrest, differentiation and apoptosis, resulting from dynamic changes in chromatin structures by accumulation of acetylated histones $(21,22,28)$. Indeed, our data show that treatment with HDAC inhibitors shows a dramatic increase in $\mathrm{p} 21^{\mathrm{WAF} 1}$ expression in MDR cancer cells (Fig. 2), which is accompanied by histone hyperacetylation (Fig. 1). Concomitantly, HDAC inhibitor treatment led to a cell cycle arrest at $\mathrm{G}_{0} / \mathrm{G}_{1}$ phase in MDR cancer cells (Fig. 4), which might be attributable to $\mathrm{p} 21^{\mathrm{WAF} 1}$ over-expression by HDAC inhibitors (Fig. 2). In addition, HDAC inhibitors show significant growth inhibition in MDR-positive cancer cells (Table I). Interestingly, all of these HDAC inhibitor effects are observed in both MDR-negative and -positive cells with similar potencies. These results strongly indicate that HDAC inhibitors are poor substrates of ABC drug transporters, which allow their intracellular accumulation for the pharmacological actions in MDR cancer cells. It is interesting that the only HDAC inhibitor harboring a cyclic tetrapeptide structure (apicidin) displays relative resistence in KBV20C cells in contrast to the hydroxamic acids (TSA and SAHA) and short chain fatty acids (valproic acid and butyrate), indicating that apicidin might be a partial substrate of $\mathrm{ABC}$ drug transporters.

In conclusion, the present study shows that HDAC inhibitors, especially SAHA, are poor substrates of ABC drug transporters and specifically downregulate MRP2 expression in MDR cancer cells, implying a possible application of HDAC inhibitors for MDR cancer treatment. These findings show the therapeutic potentials of HDAC inhibitors against MDR cancer and provide a molecular rationale for a novel application of HDAC inhibitors to overcome MDR in cancer.

\section{Acknowledgements}

This work was supported by the Korea Research Foundation Grant funded by the Korean Government (MOEHRD, Basic Research Promotion Fund) (KRF-2007-314-E00054 and KRF-2007-355-E00006).

\section{References}

1. Ambudkar SV, Kimchi-Sarfaty C, Sauna ZE and Gottesman MM: P-glycoprotein: from genomics to mechanism. Oncogene 22: 7468-7485, 2003.

2. Gottesman MM, Fojo T and Bates SE: Multidrug resistance in cancer: role of ATP-dependent transporters. Nat Rev Cancer 2: 48-58, 2002.

3. Juliano RL and Ling V: A surface glycoprotein modulating drug permeability in Chinese hamster ovary cell mutants. Biochim Biophys Acta 455: 152-162, 1976.

4. Borst P, Evers R, Kool M and Wijnholds J: A family of drug transporters: the multidrug resistance-associated proteins. J Natl Cancer Inst 92: 1295-1302, 2000.

5. Dean M, Hamon Y and Chimini G: The human ATP-binding cassette $(A B C)$ transporter superfamily. J Lipid Res 42: 1007-1017, 2001.

6. Robey RW, Polgar O, Deeken J, To KW and Bates SE: ABCG2: determining its relevance in clinical drug resistance. Cancer Metastasis Rev 26: 39-57, 2007.

7. Ling V: Multidrug resistance: molecular mechanisms and clinical relevance. Cancer Chemother Pharmacol 40 (Suppl.): S3-S8, 1997.

8. Kelly WK, O'Connor OA, Krug LM, et al: Phase I study of an oral histone deacetylase inhibitor, suberoylanilide hydroxamic acid, in patients with advanced cancer. J Clin Oncol 23: 3923-3931, 2005.

9. Munster PN, Troso-Sandoval T, Rosen N, Rifkind R, Marks PA and Richon VM: The histone deacetylase inhibitor suberoylanilide hydroxamic acid induces differentiation of human breast cancer cells. Cancer Res 61: 8492-8497, 2001.

10. Lee BI, Park SH, Kim JW, et al: MS-275, a histone deacetylase inhibitor, selectively induces transforming growth factor beta type II receptor expression in human breast cancer cells. Cancer Res 61: 931-934, 2001.

11. Ryan QC, Headlee D, Acharya M, et al: Phase I and pharmacokinetic study of MS-275, a histone deacetylase inhibitor, in patients with advanced and refractory solid tumors or lymphoma. J Clin Oncol 23: 3912-3922, 2005.

12. Carducci MA, Gilbert J, Bowling MK, et al: A Phase I clinical and pharmacological evaluation of sodium phenylbutyrate on an 120-h infusion schedule. Clin Cancer Res 7: 3047-3055, 2001.

13. Piekarz RL, Robey R, Sandor V, et al: Inhibitor of histone deacetylation, depsipeptide (FR901228), in the treatment of peripheral and cutaneous T-cell lymphoma: a case report. Blood 98: 2865-2868, 2001.

14. Sandor V, Bakke S, Robey RW, et al: Phase I trial of the histone deacetylase inhibitor, depsipeptide (FR901228, NSC 630176), in patients with refractory neoplasms. Clin Cancer Res 8: 718-728, 2002.

15. Mann BS, Johnson JR, He K, et al: Vorinostat for treatment of cutaneous manifestations of advanced primary cutaneous T-cell lymphoma. Clin Cancer Res 13: 2318-2322, 2007. 
16. Tabe Y, Konopleva M, Contractor R, et al: Up-regulation of MDR1 and induction of doxorubicin resistance by histone deacetylase inhibitor depsipeptide (FK228) and ATRA in acute promyelocytic leukemia cells. Blood 107: 1546-1554, 2006.

17. Robey RW, Zhan Z, Piekarz RL, Kayastha GL, Fojo T and Bates SE: Increased MDR1 expression in normal and malignant peripheral blood mononuclear cells obtained from patients receiving depsipeptide (FR901228, FK228, NSC630176). Clin Cancer Res 12: 1547-1555, 2006.

18. Kim YK, Kim NH, Hwang JW, et al: Histone deacetylase inhibitor apicidin-mediated drug resistance: involvement of P-glycoprotein. Biochem Biophys Res Commun 368: 959-964, 2008.

19. Kim SN, Kim NH, Lee W, Seo DW and Kim YK: Histone deacetylase inhibitor induction of P-glycoprotein transcription requires both histone deacetylase 1 dissociation and recruitment of CAAT/enhancer binding protein beta and $\mathrm{pCAF}$ to the promoter region. Mol Cancer Res 7: 735-744, 2009.

20. Kim YK, Song YJ, Seo DW, et al: Reversal of multidrug resistance by 4-chloro-N-(3-((E)-3-(4-hydroxy-3-methoxyphenyl)acryloyl)phenyl)benzamide through the reversible inhibition of P-glycoprotein. Biochem Biophys Res Commun 355: 136-142, 2007.

21. Han JW, Ahn SH, Park SH, et al: Apicidin, a histone deacetylase inhibitor, inhibits proliferation of tumor cells via induction of p21 ${ }^{\mathrm{WAF} 1 / \mathrm{Cip} 1}$ and gelsolin. Cancer Res 60: 6068-6074, 2000.
22. Marks PA, Richon VM, Breslow R and Rifkind RA: Histone deacetylase inhibitors as new cancer drugs. Curr Opin Oncol 13: 477-483, 2001.

23. Kim YK, Han JW, Woo YN, et al: Expression of p21(WAF1/Cip1) through Sp1 sites by histone deacetylase inhibitor apicidin requires PI 3-kinase-PKC epsilon signaling pathway. Oncogene 22: 6023-6031, 2003.

24. Jordan MA and Wilson L: Microtubules as a target for anticancer drugs. Nat Rev Cancer 4: 253-265, 2004.

25. Checchi PM, Nettles JH, Zhou J, Snyder JP and Joshi HC: Microtubule-interacting drugs for cancer treatment. Trends Pharmacol Sci 24: 361-365, 2003.

26. Huisman MT, Chhatta AA, van Tellingen O, Beijnen JH and Schinkel AH: MRP2 (ABCC2) transports taxanes and confers paclitaxel resistance and both processes are stimulated by probenecid. Int J Cancer 116: 824-829, 2005.

27. You JS, Kang JK, Lee EK, et al: Histone deacetylase inhibitor apicidin downregulates DNA methyltransferase 1 expression and induces repressive histone modifications via recruitment of corepressor complex to promoter region in human cervix cancer cells. Oncogene 27: 1376-1386, 2008.

28. Kwon SH, Ahn SH, Kim YK, et al: Apicidin, a histone deacetylase inhibitor, induces apoptosis and Fas/Fas ligand expression in human acute promyelocytic leukemia cells. J Biol Chem 277: 2073-2080, 2002. 